\title{
Palabras, trazos y sentidos al vuelo: dos propues- tas estéticas en Punta de plata. Bestiario
}

Words, strokes and senses in flight: two esthetic proposals in Punta de plata. Bestiario

\author{
Norma Esther García Meza \\ ORCID: 0000-0003-3616-1693 \\ ngarcia35@hotmail.com \\ Universidad Veracruzana, México. \\ Daniel Domínguez Cuenca \\ ORCID: 0000-0002-8171-1386 \\ danieldoc@gmail.com \\ Universidad Veracruzana, México.
}

Resumen:

En Punta de plata. Bestiario (2018), Juan José Arreola y Héctor Xavier logran forjar con palabras y con trazos, con líneas y silencios, dos propuestas estéticas en las que la escritura y el dibujo conviven, se entrelazan, dialogan y se iluminan mutuamente. Ambos creadores nos develan el mundo animal del que provenimos los humanos y nos hacen sentir poseedores de unos sentidos, construidos culturalmente, que nos diferencian de ellos tanto como nos igualan. Son el lenguaje, la memoria y el arte los atributos que nos distinguen, parecen decir los dos artistas con sus sentidos al vuelo.

Palabras clave:

bestiario, punta de plata, sentidos, lenguaje, memoria, arte. 
Abstract:

In Punta de plata. Bestiario, Juan José Arreola and Hector Xavier manage to forge with words and strokes, with lines and silences, two esthetic proposals in which writing and drawing coexist, intertwine, dialogue and illuminate themselves mutually. Both authors expose the animal world of which humans come from and make us feel owners of culturally constructed senses that differentiates us in as much as they liken us to them... Language, memory and art are the attribute that distinguish us, so it would seem the artists say with their senses in flight.

Key words:

Bestiary, silverpoint, senses, language, memory, art.

DOI: https://doi.org/10.36798/critlit.vi21.342

Recibido: 19 de febrero de 2020

Aceptado: 21 de agosto de 2020

Tiempo acumulado. Un montículo de polvo impalpable y milenario; un reloj de arena, una morena viviente: eso es el bisonte en nuestros días.

Juan José Arreola

... creo que en la yema de los dedos se ha concentrado mi conocimiento del mundo: todo lo que he anotado en la mente, lo he traducido hacia el tacto, todas esas zonas de piel, los olores, o lo que me dan los otros sentidos.

Héctor Xavier

\section{Presentación}

En Punta de plata. Bestiario (2018), dos propuestas estéticas dialogan, se entrelazan, conviven y se iluminan mutuamente. Las palabras de Arreola y los trazos de Xavier colocan a sus lectores frente a los animales y a la memoria que de ellos tienen, para que experimenten lo que Bajtín llama la vivencia o el "primer momento de la actividad 
estética [que consiste en] vivir (ver y conocer) aquello que está viviendo el otro" (Estética 30). Mientras Juan José Arreola recrea con palabras - "criaturas vivas" (Del Paso 199) — el ser de cada animal, Héctor Xavier lo hace con una técnica que no admite errores: punta de plata. Ambos logran, con "poética precisión" (Arreola y Xavier 8), situarnos frente a ese bestiario en el que es necesario desplegar los sentidos para percibir su presencia, ver sus movimientos, reconocer sus texturas, identificar sus olores y escuchar su bullicio. Los dos creadores establecen, así, una "relación perfecta entre palabra e imagen" (Calvino 139).

Existen muchas versiones impresas del Bestiario de Arreola, sería más adecuado decir, de sus bestiarios, que en casi todos los casos se ofrecen como recreación escrita, ya que dejan fuera los dibujos de Héctor Xavier. Al respecto, Sara Poot, estudiosa de la obra arreolina, ha señalado con acierto este rasgo del autor consistente en trasladar los textos en sus diversas publicaciones de una constelación a otra, generando con ello lo que denomina "Un giro en espiral" (Poot, Un giro 9). La propia investigadora comenta que, en la versión original de Punta de Plata. Bestiario, de la UNAM, fechada en 1958, eran 18 los textos del jalisciense, más el prólogo de nueve párrafos y 24 los dibujos del artista nacido en Tuxpan, Veracruz, colocados los textos en la solapa izquierda y los dibujos en la solapa derecha. Sin embargo, afirma que textos sobre animales escritos por Arreola aparecen en libros anteriores, así como la existencia de otros que bien podrían integrar otro bestiario total, escrito después de ese año. No tiene caso repetir aquí el meticuloso recorrido que Sara Poot hace por los diversos bestiarios de Arreola publicados hasta septiembre de 2018. Sugerimos ver el estudio de esta autora incluido en la revista Luvina, ${ }^{1}$ que brilla por ser breve y preciso.

${ }^{1}$ Nos referimos al número dedicado a Juan José Arreola, fechado en el mes de septiembre de 2018, en el que aparece el texto de Sara Poot titulado "De Punta de Plata de Juan José Arreola y Héctor Xavier al Bestiario de Arreola” (pp. 63-77). En ese mismo mes salió a la luz la nueva versión de Punta de Plata Bestiario, que nos ocupa. 
Es oportuno señalar, en cambio, que en ese mismo mes de septiembre de 2018, apareció bajo el sello de Joaquín Mortiz una edición conmemorativa por los cien años del nacimiento de Juan José Arreola, en versión impresa y electrónica, con otro diseño editorial donde alternan dibujos y textos, la cual incluye las 24 reproducciones de dibujos de Xavier, el prólogo y los 18 textos de Arreola, agregando un postfacio escrito por José Emilio Pacheco; publicación aparecida 60 años después de la original, que nos brinda una ocasión especial para hacer una nueva lectura de la obra, cuya importancia se acrecienta con los años. Es de igual manera necesario destacar que en el año 2016 se publicó el libro Héctor Xavier. El trazo de la línea y los silencios, coordinado por Angélica Abelleyra y Dabi Xavier, en coedición de la Universidad Veracruzana, el Instituto Veracruzano de Cultura y la Secretaría de Cultura, libro fundamental para dimensionar la obra del dibujante veracruzano, que conjuga testimonios, reflexiones y ensayos de críticos de arte, de amigos y de sus familiares más cercanos, así como una cuidada selección de su obra. ${ }^{2}$ A lo largo de este ensayo citaremos pasajes de este libro, así como fragmentos del video Héctor Xavier. Dibujante de la vida y de la forma, realizado por Julio Pliego, que apareció en la Serie Luz de la memoria de Canal 22, en el año 1998, obra significativa narrada por el propio Pliego con base en la entrevista que él mismo realizó a Xavier en 1994, pocos meses antes de la muerte del dibujante.

El origen de la obra es otro aspecto que requiere precisión. Miriam Kaiser señala, con justicia, que fue un dibujo de Héctor Xavier

${ }^{2}$ Consideramos que la nota publicada por la Universidad Veracruzana sobre la presentación de este libro en el 2017, ofrece información valiosa sobre su contenido: "Héctor Xavier. El trazo de la línea y los silencios [es] un libro cuidadosamente coordinado por Angélica Abelleyra y Dabi Xavier, editado por Alberto Tovalín, que reúne textos y trazos del artista veracruzano a quien Raquel Tibol consideraba que 'asumía con arrojo y paciencia el vacío de la superficie blanca y, en un acto de juicio tremendamente material, ordena la conciencia en la forma'. La edición especial está formada por seis grandes secciones que relacionan la obra de Héctor Xavier con el dibujo y el movimiento, con los trazos y la literatura, y con la esencia del artista veracruzano que, junto con Gilberto Aceves Navarro, José Luis Cuevas y Rogelio Naranjo, es considerado uno de los grandes dibujantes mexicanos del siglo XX". 
el que inspiró la idea de hacer un bestiario. El propio Arreola así lo confirma: "Yo vi en su casa el primer dibujo: la imagen del bisonte sentado que parece un grafito rupestre, y allí tomó forma otra vez la antigua idea de un bestiario" (8). La obra, entonces, está inspirada en ese primer dibujo y en la experiencia compartida durante meses de visita al zoológico de Chapultepec: “acompañé a Héctor Xavier en algunas de sus resueltas correrías de dibujante frente a difíciles modelos. Hemos visto Chapultepec a todas horas del día y a las bestias animadas o melancólicas" (9).

\section{Palabras, trazos y sentidos al vuelo}

El primer momento en que se advierte el destacado papel de los sentidos es cuando Arreola habla de la principal característica perceptible en los dibujos hechos en punta de plata:

Carentes casi de materia, los dibujos a punta de plata son los más aéreos y eternos: parecen hechos de miradas sucesivas que recaen unas sobre otras sin estorbar su transparencia, y la dureza del instrumento y la suavidad del resultado, alcanzan un ápice de poética precisión. (Arreola y Xavier 8)

Esa es la primera invitación a desplegar los sentidos, en este caso: el tacto. Con sus palabras, Arreola logra que los lectores toquemos y descubramos esa dureza en el instrumento y esa suavidad en el resultado. Pero no solo el tacto se activa. Las propuestas estéticas que están entrelazadas en Punta de plata. Bestiario abarcan todos los sentidos. Es como si ambos creadores quisieran subrayar el papel destacado que los sentidos tienen para la percepción humana del mundo ${ }^{3}$ como resultado de nuestro actuar en la esfera cultural. ${ }^{4}$

3 "Desde la antigüedad clásica, los estudios sobre la percepción humana han destacado cinco sentidos externos a través de los cuáles el cerebro recibe información sobre el mundo: la vista, el oído, el tacto, el olfato y el gusto" (Korsmeyer 15).

${ }^{4}$ Recordemos que, tal como lo plantea la antropología de los sentidos, "la 
El segundo momento es cuando relata lo que ellos han visto y nos hace ver, primero al "bisonte sentado que parece un grafito rupestre" (8) y luego "a las bestias animadas o melancólicas" (9). Las conjugaciones del verbo ver, "Yo vi" (8) y "Hemos visto" (9), nos invitan a los lectores a ver con detenimiento cómo "la Grulla Real ... hunde su pico de gualda entre el suntuoso plumaje y se despioja" (9), ver cómo el "macho de cualquier especie ... de pronto . . . percibe a la hembra y la acomete (generalmente sin éxito)" (9), ver cómo "los felinos ... van y vienen por su jaula, como reyes encarcelados y dementes" (9) y ver cómo "los monos" (9) hacen que los creadores dejen de mirar "abrumados ante tan humana estulticie" (9). Al respecto, queremos destacar que la palabra estulticie no existe. Arreola conjuga estulticia, que significa "necedad, tontería" (RAE), y especie, que en botánica y zoología agrupa los géneros y los caracteres compartidos, para nombrar a los monos. Así, bajo este término, estos se convierten en la especie de la necedad y la tontería, o de la estupidez, la bobería y la insensatez, si atendemos sus sinónimos. Es un conjunto de animales que abruma a los artistas y que, en palabras de Arreola, son vistos por nuestros ojos como quien se mira en un espejo mientras ellos: "nos miran con sarcasmo y con pena, porque seguimos observando su conducta animal" (Arreola y Xavier 87). Se trata de una propuesta estética que tiene, sin duda, un alto contenido ético y filosófico que nos recuerda las aportaciones de Bajtín sobre la importancia del otro en nuestras vidas, ${ }^{5}$ porque

percepción sensorial es cultural además de física” (Fernández Porcela 14).

5 "La falsedad y la mentira que ineludiblemente se hacen ver en la relación del sujeto consigo mismo. La imagen externa de un pensamiento, de un sentimiento, la imagen externa del alma. No soy yo quien mira desde el interior de mi mirada al mundo, sino que yo me veo a mi mismo con los ojos del mundo, con los ojos ajenos; estoy poseído por el otro. Aquí no hay integración ingenua de lo extrínseco con lo intrínseco. Espiar su propia imagen In absentia. La ingenuidad de la fusión entre el yo y el otro en la imagen especular. El excedente del otro. No poseo un punto de vista externo sobre mí mismo, no tengo enfoque adecuado para mi propia imagen interna. Desde mis ojos están mirando los ojos del otro" (Bajtín, Yo también soy 156). 
el mono ${ }^{6}$ dibujado por Héctor Xavier se convierte en un otro que nos mira y en cuyos ojos ajenos los lectores nos vemos a nosotros mismos. $^{7}$

También el oído se desata y surca el territorio de Chapultepec para captar los múltiples sonidos: "el silbato de los guardas [anunciando] que ha terminado la jornada contemplativa y . . . la enorme sinfónica bestial" (9). En ese despliegue de sonidos, el olfato, considerado por algunos estudiosos como uno de los sentidos con poco valor literario, ${ }^{8}$ se abre camino y capta lo que rodea a los animales y lo que sus cuerpos desechan:

Como las estampas, los textos proceden directamente del natural y las reflexiones que los informan tienen el mismo lugar de origen: Parque Zoológico de Chapultepec. Por eso se explican algunos rasgos de la más pura obscenidad y el aroma persistente del estiércol salvaje. (9)

Entonces, el oído se satura con los sonidos característicos de cada animal, porque al gruñir, bramar, rugir, graznar, bufar, gritar, ladrar, barritar, aullar, relinchar, ulular y crotorar van despidiendo a los artistas "con una monumental rechifla" (9). A partir de ahí los sentidos vuelan en toda la obra.

Detengámonos ahora en las miradas de ambos creadores. La mirada del escritor está estrechamente vinculada a la memoria en

${ }^{6}$ Nuestro ensayo cierra con la reproducción del dibujo de este animal.

7 "La actividad estética propiamente dicha comienza cuando regresamos hacia nosotros mismos y a nuestro lugar ... y concluimos el material de la vivencia" (Bajtín, Estética 31).

8 "El olfato y el gusto han tenido siempre escasa fortuna literaria . . . comparados con la vista y el oído son los sentidos más bajos" (Hernández Valcárcel 496). Una gran excepción es, desde luego, la novela Elperfume de Patrick Süskind (1985).

9 A manera de anécdota, Miriam Kaiser comenta: "Claro que Héctor le hizo pasar varios ratos desagradables porque conocía el movimiento de los animales y Juan José no. Un día el rinoceronte orinó de arriba a abajo a Arreola y Héctor no lo previno" (Abelleyra y Xavier 197). 
tanto que incorpora en sus textos una serie de referentes que apelan al horizonte cultural y literario de los lectores. Altamira y sus pinturas rupestres, dos leyendas medievales - la del venado que se le apareció a san Huberto y la de la cierva que amamantó al hijo de Genoveva de Brabante- la alusión a San Juan de la Cruz ${ }^{10}$ cuando menciona a Juan de Yepes, el Santo Oficio, Confucio, Lao Tsé, Utamaro, los Tártaros, doña Juana y Don Quijote, Androcles, el Vizconde de los Asilos, las metáforas griegas, la brujería medieval y Wolfgang Köhler funcionan como vehiculos de la memoria: ${ }^{11}$ una memoria literaria y artística que posee el escritor y que generosamente nos brinda a los lectores para que abrevemos en ella. La mirada del dibujante está ligada, simultáneamente, a los sentidos y a su concepción del arte de dibujar. Para él, dibujar no es resultado de una habilidad o destreza, no es un mero acto reflejo del ojo que mira, sino un ejercicio de estudio y reflexión profunda que involucra a la inteligencia, al juicio y a la conciencia. Para ilustrar lo anterior referimos una cita incluida en el ensayo "Héctor Xavier", de Angélica Abelleyra, publicado para conmemorar el décimo aniversario de la muerte del artista: "Comprendí que el dibujo es el aire, la luz, la voz, el sonido; el dibujo es lo que dice todo y llena de significado la hoja en blanco".

En el libro Héctor Xavier: El trazo de la línea y los silencios, Raquel Tibol ofrece un breve recorrido sobre diversas concepciones del arte del dibujo, señala:

Al mirar hacia el pasado se ha tomado el partido de Leonardo da Vinci, quien consideraba al dibujo como el primer instrumento para descubrir la realidad. No se opta por Piero della Francesca, donde el dibujo se definía como los 'perfiles

10 “Juan de Yepes y Álvarez, o sea, el futuro San Juan de la Cruz, nació en Fontiveros de Ávila. . . la Pascua del Bautista de 1542” (Méndez Plancarte 57).

11 "La memoria, entonces, se produce en tanto haya sujetos que comparten una cultura, en tanto haya agentes sociales que intentan 'materializar' sentidos del pasado .... en diversos productos culturales que son concebidos o que se convierten en vehículos de la memoria" (Jelin 558). 
y contornos que limitan los objetos'. El dibujo permite aprehender y asumir las concretas estructuras vivientes, y permite también concretar en líneas y trazos la exaltación concreta del espíritu o el más riguroso sentido del espacio. (Abelleyra y Xavier 18)

Dibujar es, desde la concepción estética de Héctor Xavier, de la que nos habla Alberto Dallal, penetrar en el ser como resultado de un proceso que: "consiste en deshacerse de sí mismo para penetrar airoso, triunfante en el ser" (26). El dibujante inventa su destino, desarrolla la capacidad de penetrar en el ser de otro y de recrear la experiencia en la forma, dejar que el ser otro se manifieste en la línea que lo contiene o lo sugiere, según sea el caso.

Dibujar, entonces, es un acto ético y estético que involucra todos los sentidos y, a la vez, es una forma de trascendencia, de ordenación de la conciencia. Para explicarlo Tibol se sirve de la voz de los propios dibujantes:

Vlady sostuvo certeramente que dibujar es una manera de reflexionar, de meditar. Hay que percibir el dibujo como una forma de la inteligencia. . . Dialécticamente Vlady considera que sólo el desorden da la oportunidad de un nuevo orden. [Héctor Xavier] exalta la dificultad de no recurrir al claroscuro y materializar el dibujo en una línea o en una variedad de líneas.... Se trata de asumir con arrojo y paciencia ... el vacío de la superficie blanca y, en un acto de juicio tremendamente material, ordenar la conciencia en la forma. (18-19)

El trabajo creativo del dibujante lleva a descubrir nuevas y recónditas identidades, es un nombrar de nuevo al ser, en tanto que este renace de su mano:

En estos dibujos de Héctor Xavier está impreso el nombre, no el original —el conocido— sino el que toman de las líneas del dibujo, las que le dan identidad, las que inventan el nuevo llamado de su ser distinto, secreto, y llevan una memoria, llevan un sentimiento, un olor. Animales anticipación del 
hombre, uno puede reconocer su noble o feroz origen animal y reconocerse en ellos y decir con dignidad zoológica o humana - lo mismo da-decirse antes fui rinoceronte, o ave, o cuadrúpedo, y ahora soy (ya evolucionado) soy simplemente un mono, un simio, un bípedo semoviente. (Pliego 2:18-3:22)

Así, cuando a partir de la mirada atenta y del trazo creador de Héctor Xavier aparece el dibujo del búho, Arreola nos dice que, como si fuera una columna de plumas labradas, el búho "apoya todas las metáforas griegas" (64). El autor se refiere, de este modo, a las metáforas con las que Ovidio narra, en el libro V de Metamorfosis, el rapto de la hija de Ceres, Proserpina, y cómo el delator se convierte en un ave odiosa que:

se arropa bajo alas de color azafrán, crece aumentando el tamaño de su cabeza, curva sus largas uñas y apenas mueve en sus perezosos brazos las plumas que allí le han nacido, y se convierte en un repulsivo pajarraco que presagia próxima desgracia, un torpe búho, siniestro augurio para los mortales. (Ovidio 141)

Cuando Héctor Xavier nos presenta al ciervo, Arreola dice que "avanza ... como una aparición ya sea en el prado de Chapultepec o desde un boscaje de leyenda" (40). Se refiere, así, a dos leyendas medievales: la del "Venado de san Huberto que lleva una cruz entre los cuernos" (40) 12 y la de la "cierva que amamanta a Genoveva de Brabante" (40). ${ }^{13}$ Termina su reflexión con la composición de una

12 "Aunque este santo pertenece por cronología a los siglos VII y VIII fue en el siglo XX cuando su leyenda terminó de perfilarse incluyéndose en su proceso de conversión la visión del ciervo crucífero cuando iba de caza" (Gómez Bárcena 423).

${ }^{13}$ En el libro $A l$ margen de la ilustración: cultura popular, arte y literatura en la España, los autores nos ofrecen datos interesantes sobre Genoveva de Brabante y sostienen que fue un personaje: "inexistente históricamente . . . pero cuya existencia literaria popular fue reiteradísima tanto en prosa como en verso y tam- 
pareja fabulosa formada por los protagonistas de ambas leyendas: el ciervo crucífero y la cierva amamantadora.

Del avestruz fijado en el dibujo por la mirada indagadora y la mano diestra de Héctor Xavier, el escritor nos dice:

Destartalado, sensual y arrogante, el avestruz representa el mejor fracaso del garbo, moviéndose siempre con descaro, en una apetitosa danza macabra. No puede extrañarnos entonces que los expertos jueces del Santo Oficio idearan el pasatiempo o vejamen de emplumar mujeres indecentes para sacarlas desnudas a la plaza. (51)

Arreola alude, así, a una de las prácticas correctivas del Santo Oficio de la Inquisición contra la bigamia: el emplumar, ${ }^{14}$ castigo que consistía en untar miel en el cuerpo del culpable y cubrirlo con plumas. ${ }^{15}$

bién llegó al teatro . . ¡ ¡Difícil ejemplo el de la vida de Santa Genoveva! Es, más bien, un cuento en el que se acumulan detalles como el de las calumnias, la venganza del marido que quiere matarla a ella y al hijo por creerla infiel y encarga a unos criados que den constancia de su muerte llevándole la lengua de la Princesa. Naturalmente, los criados se apiadan dejan con vida a la madre y al hijo, mientras llevan al Príncipe la lengua de un perro. En el monte boscoso en que son abandonados, la Princesa se queda sin leche para amamantar al niño, pero una cierva que aparece milagrosamente cumplirá esa tarea" (Huerta Calvo y Palacios Fernández 71-73).

14 "Emplumar. Vale tambien castigar a uno y afrentarle, por haver sido alcahuete: lo que se executa por mano del Verdúgo desnudándole de medio cuerpo arriba, untándole con miel, y después cubriéndole con pluma menuda. Latín. Plumas ad ignominiam alicui affigere.PIC. JUST. f. 7. Digo que del mal el menos: mas quiero ser pelada que emplumada. QUEV. Mus. 5. letr. Satyr. 2. Las viejas son emplumadas, por darnos con que volemos" (Diccionario de Autoridades).

15 “García de Trasmiera recuerda la práctica, en su época ya desaparecida, de algunas otras sanciones, probablemente enmarcadas en el Ámbito del Derecho municipal: 'Desnudo el reo -escribe-, se le unta el cuerpo con miel y se recubre con plumas de aves; de este modo, atormentado por las moscas, se le exhibe en la picota, en público deshonor. A esto se llamaba emplumar, y se hacía también con las prostitutas"” (Gacto Fernández 480). Solange Alberro también refiere 
Arreola logra que los lectores veamos las deposiciones, defecaciones, excreciones, evacuaciones, boñigas, excrementos, suciedades e inmundicias que desechan las aves de rapiña y que sintamos, como él y Héctor Xavier, el olor que emanan: "Todos, halcones, águilas o buitres, repasan como frailes silenciosos su libro de horas aburridas, mientras la rutina de cada día miserable les puebla el escenario de deyecciones y de vísceras blandas: triste manjar para sus picos desgarradores" (46). Proliferan en el zoológico los olores nauseabundos porque las focas desprenden un "olor intenso y repulsivo" (25) y la hiena "lleva un bolsillo de almizcle corrompido entre las piernas" (31), esa "sustancia grasa, untuosa y de olor intenso que algunos mamíferos segregan” (RAE).

El olfato, entonces, tiene un lugar destacado en la obra porque, para lograr captar con nitidez cada uno de los animales dibujados, Héctor Xavier no solo los miró detenidamente, sino que los olió, los olfateó, los respiró. Al respecto, Sara Poot refiere lo siguiente:

En una entrevista de 1981 dijo Héctor Xavier a Alberto Dallal: '... puedo afirmar que el bestiario Punta de plata fue realizado dentro de las jaulas del zoológico de Chapultepec. No era yo un espectador, no tomaba fotografías ni filmaba, sino que me hallaba adentro, en directo, para sentir la presencia del animal, lo respiraba, y digo respirar porque aún percibo a lo que huele, lo que suda, su calor, todo. Asumía y forjaba toda su visión, no tan sólo óptica sino orgánica. (De Punta 76).

En Punta de plata. Bestiario Juan José Arreola y Héctor Xavier se erigen como forjadores de una obra artística que hace desplegar las manos, abrir los ojos y los oídos, aguzar la nariz y sentir en la boca

este castigo que consistía en "la exposición de algunos pecadores con el cuerpo embardunando de miel y emplumado"; y, en nota al pie, nos ofrece la siguiente información: "El emplumamiento fue aplicado al menos una vez por el Santo Oficio mexicano, en la persona del andaluz Juan Márquez de Andino, testigo falso, condenado el 29 de agosto de 1664" (193). 
la repugnancia por todo aquello que ama la hiena: "el fuerte sabor de las carnes pasadas" (31):

Estos animales de Héctor Xavier — los del Bestiario- en contemplación paradisiaca, yacientes, melancólicos, entregados a la autocontemplación de su ser animal, ausentes a compulsión alguna por hacer, nimbados por pereza ontológica, ajenos al apuro compulsivo de Héctor Xavier para aprehenderlos en sus líneas impresas con punta de plata al rojo, lo hecho ahí queda, es inmodificable, sus animales están celebrando la vida. (Pliego 3:24-4:08)

Este despliegue de los sentidos culmina con el papel protagónico del oído, del oído atento de José Emilio Pacheco, porque los textos escritos que conforman Punta de plata. Bestiario son resultado de un ejercicio de oralidad, ${ }^{16}$ un acto que involucra la palabra dicha y escuchada:

Todo se resume en una frase: Bestiario, obra maestra de la prosa mexicana y española, no es un libro escrito: su autor lo dictó en una semana. Otros hubiéramos necesitado de muchos borradores para intentar aproximarnos a lo que en Arreola era tan natural como el habla o la respiración. A la distancia de los años transcurridos, esta inmensa capacidad literaria me admira tanto como entonces. Algunos de sus textos, si la memoria no miente, son anteriores a esos días de diciembre de 1958: 'Prólogo', 'El sapo', 'Topos', y quizás haya alguno posterior como 'El ajolote'. Sin embargo, la mayoría resuena en mi interior como los escuché por primera vez, los escribí con

16 “El término 'oralidad' se refiere al lenguaje como sonido articulado para ser hablado y oído. La comunicación oral se expresa a través de la voz y su potencial se encuentra en ser narrada. El lenguaje es abrumadoramente oral. Comunicación verbal y pensamiento se relacionan con el sonido. La gestualidad sustituye a las palabras y, las imágenes, por elocuentes que sean, siempre se sitúan en un contexto de palabras. Toda historia antes de ser escrita fue contada" (Szurmuk y Mckee Irwin 197). 
una pluma Sheaffer de tinta verde y los pasé a una máquina Royal para que Arreola les diera forma definitiva. (Pacheco cit. en Arreola y Xavier 91)

Fue así como José Emilio Pacheco se convirtió en amanuense de Juan José Arreola, es decir: escribiente, copista, escribano y calígrafo, que son algunos de los sinónimos del término que el poeta utiliza para titular el texto con el que rinde homenaje a quien fue su maestro. "Amanuense" viene del latín amanuensis y significa "persona que tiene por oficio escribir a mano, copiando o poniendo en limpio escritos ajenos, o escribiendo lo que se le dicta" (RAE). Eso es, precisamente, lo que José Emilio Pacheco hizo y nos lo cuenta detalladamente en los seis apartados que conforman el texto que cierra Punta de plata. Bestiario:

Ya no recuerdo si la idea fue mía o de Vicente Leñero, Eduardo Lizalde o el propio Fernando del Paso ... Sea como fuere, el 8 de diciembre, ya con el agua al cuello, me presenté en Elba y Lerma a las nueve de la mañana, hice que Arreola se arrojara en su catre, me senté a la mesa de pino, saqué papel, pluma y tintero y le dije:

- No hay más remedio. Me dicta o me dicta.

Arreola se tumbó de espaldas en el catre, se tapó los ojos con la almohada y me preguntó:

— ¿Por cuál empiezo?

Dije lo primero que se me ocurrió:

- Por la cebra.

Entonces, como si estuviera leyendo un texto invisible, el Bestiario empezó a fluir de sus labios: 'La cebra toma en serio su vistosa apariencia, y al saberse rayada, se entigrece. Presa de su enrejado lustroso, vive en la cautividad galopante de una libertad mal entendida'.

Y así, el 14 de diciembre escuché el final del libro: 'Para el macho que tiene sed, el camello guarda en sus entrañas rocosas la última veta de humedad; para el solitario, la llama afelpada, redonda y femenina, finge los andares y la gracia de una mujer ilusoria'. (96-97) 
Gracias al cuidadoso ejercicio de identificación de los textos escritos antes y después de 1958, realizado por Sara Poot en el artículo ya citado, hoy es posible saber que el prólogo y los 18 textos publicados en la edición de 2018 son los mismos que aparecen en la de aquella lejana fecha y, salvo alguna corrección mínima de puntuación, el único cambio en el contenido es la inclusión del postfacio de Pacheco, que constituye un acierto. Lo que sí diferencia sustancialmente a las dos ediciones es el diseño: la edición conmemorativa no separa los textos de Arreola en una solapa (Bestiario) y los dibujos de Xavier en otra (Punta de Plata), sino que hay un trabajo con la tipografía y las imágenes que le confiere otro ritmo a la lectura. No obstante, esta edición privilegia la divulgación y descuida la calidad de la impresión que merece el dibujo en punta de plata, ${ }^{17}$ además se añaden plantas y adornos que, aunque atractivos para los nuevos lectores, desvirtúan y alteran el dibujo original. Vale la pena mencionar que también se reproduce un error común de apreciación al incluir la leyenda "Ilustrado por Héctor Xavier" porque, como ya vimos, el dibujante no ilustra los textos, sino que Arreola escribe a partir del dibujo del bisonte, en un trabajo que después se desarrolla en largas jornadas compartidas de observación, vivencia y reflexión en el zoológico.

\section{Dos propuestas estéticas que nacen de lo artesanal}

Queremos cerrar el presente ensayo destacando que ambas propuestas estéticas nacen de lo artesanal, entendido como aquel tipo de trabajo que el artista realiza con sus manos hasta lograr forjar su obra. En el prólogo de Punta de plata. Bestiario, Juan José Arreola ha-

${ }^{17}$ Si se observa con detenimiento, todo parece hecho a tinta, lo cual es hasta cierto punto entendible porque se busca la divulgación mediante el tiraje de una mayor cantidad de ejemplares, pero no deja de ser una pena pues no permite que se aprecie la estética de la técnica empleada por Xavier. Al respecto, sería deseable que Mortiz realizara una edición especial, limitada, con otro costo, en la que se cuide con pasión y esmero la reproducción de tan finos dibujos. 
bla de este rasgo estético al describir el proceso de elaboración del instrumento que le permitió a Héctor Xavier la elaboración precisa y admirable de cada una de sus líneas:

En nuestros días las puntas de plata se han vuelto una curiosidad en el taller del pintor, a pesar de los aciertos de Leonardo, y las de oro son rarísimas. Héctor Xavier introdujo en el porta-minas un alambre de plata mexicana, lo afiló en el raspador y obtuvo así un estilete práctico y económico. Y con él y una carpeta de hojas preparadas se fue al aire libre de Chapultepec a vivir ocho meses entre los animales enjaulados. (8)

En el video que Julio Pliego realizó sobre la vida y obra de Héctor Xavier se mencionan las palabras con las que José Revueltas reseña la obra del dibujante. Palabras que destacan la perfección del trazo que la mano de Héctor Xavier, empuñando el instrumento artesanal, construido por él mismo, logra en cada dibujo:

Hay un torso cuya línea desciende por el cuerpo desnudo y que desaparece quien sabe cuánto tiempo antes de llegar al pie, este evadirse de la línea sólo es una concesión a la nostalgia de infinito que la forma tiene, del tiempo en que no precisaba aún su propio espacio... Pero cuando la línea reaparece la forma se refrenda en su presencia y afirma sus límites tangibles de cosa ya soñada, contenida. Son las líneas, así, las que sueñan a las formas que aguardan durante largos años de vigilia el momento de poder contenerlas entre ellas, hasta que llega el artista y las invita. . . . Llega Héctor Xavier y las líneas se someten enseguida a sus inventos nupciales. Hacen manos, torsos, rostros, cuerpos desnudos, pensadores, conocidas especies de misteriosa zoología, tremendas aves de mirar penetrante y atroces y acosadas vestiduras, antiguos muslos humanos, igual que columnas helénicas, estupefactos monstruos de estirpe entristecida, pescados herméticos, bestias meditabundas, monos de todas las familias del hombre en el destierro. La realidad del sueño, en fin, el sueño realizado. (Pliego 15:41-17:42) 
El propio Héctor Xavier habla de este contacto físico con el portaminas al destacar la yema de sus dedos concentrando toda su capacidad creativa:

Cuando me preguntan cómo escojo a mis modelos, contesto enseguida: por el tacto. Y creen que exagero pero no. Es una respuesta instantánea. Además, nadie se me resiste. Pregunto ‘¿se puede?'. Impongo mi tacto que es el que realmente sabe. Alguien pensó que era una suerte de procedimiento fotográfico a través del tacto, pero no. Uso la capacidad sensible, la capacidad táctil porque creo que en la yema de los dedos se ha concentrado mi conocimiento del mundo: todo lo que he anotado en la mente, lo he traducido hacia el tacto, todas esas zonas de piel, los olores, o lo que me dan los otros sentidos. (Abelleyra y Xavier 29).

Porque en el momento preciso en el que el dibujante desplaza la punta de plata sobre esas "hojas preparadas" (Arreola y Xavier 8), hojas sensibles a la herida argentina del estilete con las que Héctor Xavier se fue "al aire libre de Chapultepec" (8), no solo cuentan los trazos de la línea, sino también su ausencia, los accidentes y hallazgos del dibujo. Líneas que se pierden y reaparecen con un nuevo significado que complementan la imagen del animal ante nuestros ojos asombrados. Julio Pliego se refiere a este proceso creativo con el que Héctor Xavier logra que aparezca frente a nuestros ojos la porción bumana de cada animal:

Héctor Xavier de frente a las fieras que llevaba al papel con líneas entrañables: fuertes, suaves, leves, intensas todas. Recreaba la porción humana que lleva todo animal. De su mano salía un zoológico de fieras dóciles y otros animales con rasgos complacientes, inmutables, que meditaban sobre el tiempo y la existencia. Los trazos de Héctor Xavier humanizaron a los animales... (Pliego 0:22-0:58)

Así como Héctor Xavier afinó el alambre de plata colocado en el portaminas, que es un ejercicio totalmente manual que le permite 
alcanzar la perfección en el trazo, así también Arreola lima sus textos con esa pasión artesanal heredada de uno de sus tíos maternos: "De alguna manera extraña, heredé de él una pasión artesanal que él aplicaba al acero y yo al lenguaje. Él limaba, y era un artífice en eso. Yo limo el lenguaje" (en Del Paso 142); logra, así, forjar textos memorables. Esa pasión artesanal por el lenguaje es la síntesis de su visión artística del mundo: "hay nobleza en mi palabra. Palabra de honor. Procedo en línea recta de dos antiquísimos linajes: soy herrero por parte de madre y carpintero a título paterno. De allí mi pasión artesanal por el lenguaje" (Arreola, Confabulario 8).

El resultado de este encuentro creativo fue publicado por primera vez en $1958^{18}$ bajo el título Punta de plata. Bestiario. En El último juglar: Memorias de Juan José Arreola, el escritor dejó testimonio de esa experiencia compartida:

A finales de 1958 retomé mi actividad de editor. Sentí que era un momento propicio para echar a andar una nueva editorial que se llamaría Cuadernos del unicornio. Durante muchas tardes Héctor Xavier y yo recorrimos juntos el zoológico de Chapultepec, para que los animales nos vieran a nosotros. Nos quedábamos parados largo rato ante las jaulas, y por algunos instantes creíamos que estábamos en las selvas africanas. Fue cuando Héctor realizó los maravillosos dibujos de

18 Aunque hay algunos autores que consignan su aparición en 1959. Al respecto, Sara Poot sostiene lo siguiente: "los textos difícilmente pudieron acabarse de imprimir el 24 de diciembre de 1958, puesto que, según José Emilio Pacheco, Juan José Arreola los dictó (a él, JEP) del 8 al 14 de diciembre de 1958 y fueron entregados a la UNAM el día 15. Lo que se dice en el colofón de Punta de plata, aunque contiene una fecha 'epifánica', no parece corresponder a la realidad de los hechos, lo que por supuesto no cambia su importancia. Pero, ¿qué fecha citar como año en que aparecen 'los textos de este Bestiario' y con él reunidos los dibujos de Héctor Xavier? Según el colofón, tendría que ser 1958, sabiendo que el libro álbum habrá aparecido en 1959. Al ver al 'bisonte sentado', Arreola volvió a la idea del bestiario, mientras (comenta) que Héctor Xavier 'vivió' ocho meses con los animales de Chapultepec. 1958 es el año clave" (64). También Julio Pliego, en el documental referido, alude a la obra como publicada en 1959. 
Punta de plata y yo escribí los textos de mi Bestiario. Héctor ejecutó sus dibujos de animales con la técnica que utilizaron los pintores del renacimiento italiano: la punta de plata. Por esos días, me regaló un precioso dibujo que era la cabeza de un unicornio. Fue ese unicornio con su cuerno alargado el que me inspiró para hacer los cuadernos, el diseño de las portadas. El libro Punta de plata fue editado por la Universidad Nacional Autónoma de México, y salió de las prensas en diciembre de 1958. Me hice cargo del diseño y el cuidado de la edición. Hice una carpeta de artista para guardar los 24 dibujos y los textos. Casi nadie recuerda esta publicación puesto que fue limitada a 500 ejemplares. Estuvo agotada durante más de treinta años. (Arreola, El último juglar 330)

En el párrafo citado resulta evidente cómo Arreola, quien además de escribir también ensayó el dibujo y la pintura, ${ }^{19}$ aprecia de modo significativo el arte creado por Héctor Xavier. Artista que, como se aprecia en el fragmento que citamos a continuación, no solo se ocupó de dibujar animales sino también de realizar retratos, autorretratos, desnudos, flores y paisajes, entre muchos otros aportes creativos que conforman su obra:

Obsesionado del retrato y autorretrato, autor de series tan memorables como su Bestiario trabajado a la punta de plata con los animales del Bosque de Chapultepec (con textos de Juan José Arreola) y sus desnudos Eróticos, Xavier amaba plasmar el cuerpo en movimiento. Lo hizo con bailarinas del Senegal y con Pilar Rioja y Rudolf Nureyev; plasmó la dignidad y fuerza de sus Viejos y los Rabinos; develó la sensualidad de sus flores y paisajes acuáticos de 360 grados; participó en escenografías para Poesía en Voz Alta e ilustró libros de

\footnotetext{
${ }^{19}$ Según se observa en el libro Perdido voy en busca de mí mismo. Poemas y acuarelas, compilado por Orso Arreola y publicado por el Fondo de Cultura Económica en el 2018.
} 
Efraín Huerta, Jaime Labastida y Oscar Oliva.(cit. en Abelleyra, "Héctor Xavier")

Pero regresemos a la rememoración de esa primera edición y escuchemos, primero, la mención que de ella hace Julio Pliego en el video ya referido: "En 1959, un Bestiario, con dibujos de Héctor Xavier y textos de Juan José Arreola, publicado por la Universidad Nacional, constituyó un sonado éxito editorial, literario y artístico" (Pliego 2:00-3:21). Veamos ahora cómo Miriam Kaiser, compañera de vida de Héctor Xavier, comenta desde una perspectiva crítica esta misma publicación en la que el dibujante aparece en calidad de ilustrador de textos: ${ }^{20}$

El resultado fue el álbum Punta de plata, que es una hermosura desde el punto de vista del diseño, tipografía, aunque tiene una cubierta o tapa lamentable de cartulina ... se editaron solamente 500 ejemplares y muy pocos estuvieron a la venta. El libro pasó desapercibido. Tiempo después Arreola tuvo la suerte de que le publicaran el Bestiario. Éste entró a la literatura, cosa que no sucedió con los animales. Así, por muchos años hemos oído que Héctor Xavier ilustró los cuentos de Juan José Arreola mientras que, en estricto sentido, debe ser que Juan José Arreola escribió para los dibujos de Héctor Xavier. (cit. en Abelleyra y Xavier 201).

Ha sido nuestro interés a lo largo de este ensayo destacar que Punta de plata. Bestiario contiene dos propuestas estéticas que dialogan, se entrelazan, conviven y se iluminan mutuamente. ${ }^{21}$ La obra

${ }^{20}$ Como ya señalamos, la edición de 2018 reproduce este mismo error: la portada abre con la leyenda: "Ilustrado por Héctor Xavier".

${ }^{21}$ En la última sección del libro de Abelleyra y Xavier, hay un apartado dedicado a testimonios de la familia e hijos. Tamari Xavier señala lo difícil que era reunir la obra de su padre y destaca la exposición realizada en Veracruz en 2006, con curaduría de su madre Miriam Kaiser, en el Espacio Cultural Casa Principal, del Instituto Veracruzano de Cultura. Por coincidencia, Daniel Domínguez 
en su conjunto excede a la suma de dos individualidades y se hace un todo que multiplica las rutas de lectura, las posibilidades de disfrute y de significado. No es uno, no son dos, son otros, somos otros al adentrarnos en su universo. Ambos creadores logran forjar con palabras y con trazos, con líneas y silencios, dos propuestas estéticas que nos develan que el mono renunció siglos atrás a la tentación de ser humano, que fue inútil intentar dejar el paraíso: ellos lo miran, el mono los mira y él nos mira desde ese mundo animal del que provenimos los humanos. Los autores de Punta de plata. Bestiario nos hacen sentir poseedores de unos sentidos, construidos culturalmente, que nos diferencian de los animales tanto como nos igualan. Son el lenguaje, la memoria y el arte los atributos ${ }^{22}$ que nos distinguen, parecen decir los dos artistas con sus sentidos al vuelo.

Cuenca, uno de los autores de este ensayo, dirigió ese espacio cultural desde mediados del año 2000 hasta febrero de 2007. Fue durante dicha exposición que pudo tratar a Miriam Kaiser y entablar una perdurable amistad. Fue ella quien nos facilitó el estupendo video de Julio Pliego, realizado con Canal 22, un registro muy valioso al que valdrá la pena dedicarle un artículo aparte. Miriam expresaba su orgullo por poder exponer la obra de un veracruzano (tuxpeño) en un espacio cultural del Estado que lo vio nacer. Puesto que, de acuerdo con su testimonio, no fue el dibujante quien ilustró los textos de Arreola, sino que fue Juan José quien escribió sus textos a partir de los dibujos de Héctor Xavier, incorporamos los apellidos de ambos artistas en nuestras citas.

${ }^{22}$ Atributos que forman parte de la cultura, entendida como: "una inteligencia colectiva y una memoria colectiva, esto es, un mecanismo supraindividual de conservación y transmisión de ciertos comunicados (textos) y de elaboración de otros nuevos" (Lotman 109). Entendida también como: "el conjunto de hechos simbólicos presentes en una sociedad... O, más precisamente, como la organización social del sentido, como pautas de significados 'históricamente transmitidos y encarnados en formas simbólicas, en virtud de las cuales los individuos se comunican entre sí y comparten sus experiencias, concepciones y creencias"' (Giménez). 


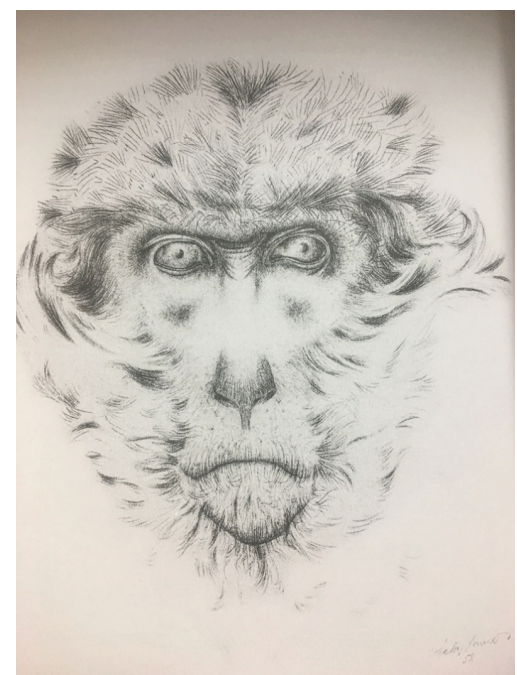

Dibujo de mono por Héctor Xavier en Punta de plata. Bestiario, 2018, p.84.

\section{Bibliografía}

Abelleyra, Angélica. "Héctor Xavier". La Jornada semanal, www.jornada.com.mx/2004/08/01/sem-abelleyra.html

Abelleyra, Angélica y Dabi Xavier. Héctor Xavier. El trazo de la línea y los silencios. UV/IVEC/ Secretaría de Cultura, 2016.

Alberro. Solange. Inquisición y sociedad en México, 1571-1700. Fondo de Cultura Económica, 2013.

Arreola, Juan José. Confabulario. Joaquín Mortiz, 2002.

Perdido voy en busca de mí mismo. Poemas y acuarelas. Compilado por Orso Arreola, Fondo de Cultura Económica, 2018.

Arreola, Juan José y Héctor Xavier. Punta de plata. Bestiario. Joaquín Mortiz, 2018.

Arreola, Orso. El último juglar. Memorias de Juan José Arreola. Diana, 1998.

Bajtín, Mijaíl. Yo también soy (fragmentos sobre el otro). Colección La huella del otro, selección, traducción, comentarios y prólogo de Tatiana Bubnova, Taurus, 2000. 
. Estética de la creación verbal. Traducción de Tatiana Bubnova, Siglo XXI, 1995.

Calvino, Italo. Por qué leer los clásicos. Tusquets, 1992.

Del Paso, Fernando. Memoria y olvido de Juan José Arreola. Fondo de Cultura Económica, 2003.

“Entrevista a Héctor Xavier”. Agradecimientos a Miriam Kaiser y Rodolfo Sánchez Alvarado, Filmoteca de la Universidad Autónoma de México, 1994, Pliego, Héctor Xavier. Dibujante de la vida y de la forma. Documental.

Fernández Poncela, Anna María. "Antropología de las emociones y teoría de los sentimientos". Revista Versión, Nueva Época, junio 2011, no. 26, pp. 1-24.

Gacto Fernández, Enrique. "El delito de bigamia y la Inquisición española". Anuario de historia del derecho español, 1987, no. 57, pp. 465-492.

Giménez Montiel, Gilberto. "La concepción simbólica de la cultura". Teoría y análisis de la cultura, Conaculta / ICOCULT, 2005, pp. 67-68.

Gómez Bárcena, María Jesús. “¿San Eustaquio o San Huberto? Un santo cazador en el retablo del Árbol de Jesé en la capilla del obispo Acuña de la catedral de Burgos". Anales de la Historia del Arte, 1993-1994, no. 4, pp. 419-430.

Hernández Valcárcel, Carmen. La expresión sensorial en 5 poetas del 27. Universidad de Murcia, 1978.

Huerta Calvo, Javier y Emilio Palacios Fernández. Al margen de la ilustración: cultura popular, arte y literatura en la España. Rodopi, 1994.

Jelin, Elizabeth, "Subjetividad y esfera pública: el género y los sentidos de familia en las memorias de la represión", en Política y Sociedad, 2011, vol. 48, no. 3, pp. 555-569.

Lotman, Iuri M. La semiosfera I. Semiótica de la cultura y del texto. Selección y traducción del ruso por Desiderio Navarro, Ediciones Cátedra, 1996,

Korsmeyer, Carolyn. El sentido del gusto. Comida, estética y filosofía. Paidós, 2002. 
Méndez Plancarte, Alfonso. "San Juan de la Cruz en Méjico". San Juan de la Cruæ. Pensamiento y poesía. Universidad iberoamericana, 1990.

Ovidio. Metamorfosis. Gredos, 2016.

Pliego, Julio. Héctor Xavier. Dibujante de la vida y de la forma. Serie Luz de la memoria, guion de Julio Pliego, montaje de imagen por Mateo Pliego Basail y Julio Pliego, fotografías de Héctor Xavier con José Revueltas por Héctor García, postproducción de Gerardo Mendieta M., generación de caracteres por Adriana Vera, Canal 22, Copyright Televisión Metropolitana S.A. de C.V., 1998. Documental.

Poot, Sara. "De Punta de plata de Juan José Arreola y Héctor Xavier al Bestiario de Arreola". Luvina, no. 92. 2018, pp. 63-77.

- Un giro en espiral. El proyecto literario de Juan José Arreola y otros ensayos sobre su obra. Universidad Nacional Autónoma de México, 2009.

Real Academia Española. Diccionario de Autoridades. Tomo I, 1732, web.frl.es/DA.html

. Diccionario de la Real Academia. 2020, dle.rae.es/estulticia

Revueltas, José. "Las líneas invitadas". Pliego, Héctor Xavier. Dibujante de la vida y de la forma. Documental.

Szurmuk, Mónica y Robert Mckee Irwin, coordinadores. Diccionario de estudios culturales latinoamericanos. Siglo XXI Editores / Instituto Mora, 2009.

Universidad Veracruzana. UV presentará libro sobre Héctor Xavier, artista tuxpeño. Facultad de Artes Plásticas - Xalapa, Noticias, 11 mayo 2017, www.uv.mx/artesplasticas/noticias/uv-presentara-libro-sobre-hector-xavier-artista-tuxpeno/ 